OPEN ACCESS

Edited by:

Kashif Ali,

Shaheed Zulfiqar Ali Bhutto Institute of

Science and Technology, Pakistan

Reviewed by:

Hammad Kayani,

Shaheed Zulfiqar Ali Bhutto Institute of

Science and Technology, Pakistan

Sahrish Muneer Uddin,

Aga Khan University, Pakistan

Fatima Aziz,

Aga Khan University, Pakistan

*Correspondence:

Samreen Sarwar

sarwarsamreen3@gmail.com

Specialty section:

This article was submitted to Disaster and Emergency Medicine,

a section of the journal

Frontiers in Public Health

Received: 28 August 2021 Accepted: 17 November 2021 Published: 17 December 2021

Citation:

Muhammad J, Sarwar S, Khan T,

Qasmi SA, Ikram A, Ahmad G, Zahid M, Durrani RH and Ahmed F (2021) A Cross-Sectional Survey to Assess Biorisk Management System

in Research and Diagnostic Laboratories in Khyber Pakhtunkhwa,

Front. Public Health 9:766162. doi: 10.3389/fpubh.2021.766162

\section{A Cross-Sectional Survey to Assess Biorisk Management System in Research and Diagnostic Laboratories in Khyber Pakhtunkhwa, Pakistan}

\author{
Javed Muhammad ${ }^{1}$, Samreen Sarwar ${ }^{2 *}$, Tariq Khan ${ }^{3}$, Shamsul Arfin Qasmi ${ }^{4}$, \\ Aamer Ikram ${ }^{5}$, Ghufran Ahmad ${ }^{6}$, Maria Zahid ${ }^{7}$, Rida Haroon Durrani ${ }^{8}$ and Furqan Ahmed ${ }^{9}$ \\ ${ }^{1}$ Department of Microbiology, University of Haripur, Haripur, Pakistan, ${ }^{2}$ Department of Microbiology, University of Health \\ Sciences Lahore and Technical Advisor, Health Security Partners, Lahore, Pakistan, ${ }^{3}$ Department of Biotechnology, \\ University of Malakand, Chakdara, Pakistan, ${ }^{4}$ Department of Pathology/Microbiology, Fazaia Ruth Pfau Medical College, \\ Karachi, Pakistan, ${ }^{5}$ National Institute of Health, Islamabad, Pakistan, ${ }^{6}$ NUST Business School, National University of \\ Sciences and Technology (NUST), Islamabad, Pakistan, ${ }^{7}$ Molecular Pathology Department, Dow University of Health \\ Sciences, Karachi, Pakistan, ${ }^{8}$ University Diagnostic Laboratory, Central Laboratory Complex, the University of Veterinary and \\ Animal Sciences, Pattoki, Pakistan, ${ }^{9}$ Department of Prevention and Evaluation, Leibniz Institute for Prevention Research and \\ Epidemiology, Bremen, Germany
}

Financial, cultural, and managerial hurdles have made biosafety and biosecurity measures difficult in resource-constrained countries like Pakistan. Because of increasing awareness of biorisk management, diagnostic and research laboratories have made major advances in biosafety and biosecurity in the recent decade. As a result, identifying and addressing gaps in biorisk management has never been more critical. The purpose of this study was to assess the current situation of personal protective equipment (PPE), biosafety behavior, waste management, biosafety and biosecurity measures, training and safety, and health services in diagnostic and research laboratories across Pakistan's Khyber Pakhtunkhwa (KP) province. We adapted the WHO Laboratory Assessment tool (2012) and CWA 15793 (Biorisk management guidelines) for conducting a cross-sectional survey, which was distributed among various laboratories in KP. The survey included 30 laboratories, including 11 diagnostic and 19 research laboratories. In comparison to diagnostic laboratories, biorisk management practices in research laboratories were better in terms of PPE, biosafety behavior, waste management, biosafety measures, biosecurity measures, trainings, and safety and health services. KP laboratories' biorisk management practices have improved over time, according to our findings. However, we were able to identify inadequacies that would require considerable improvements to the current setups based on the WHO and CWA 15793 recommendations. Organizations can tailor their biosafety measures and training to address identified gaps using the presented KP snapshot.

Keywords: biosafety, laboratories, Khyber Pakhtunkhwa, Pakistan, biorisk management 


\section{INTRODUCTION}

To avoid laboratory-acquired infections and control the spread of potentially hazardous agents in the environment, diagnostic and research laboratories must maintain a safe and secure environment (1). For safe and secure practices, laboratories must have a complete Biorisk Management (BRM) system that complies with the Global Health Security Agenda (GHSA) and bioethical guidelines (1-3).

Laboratory BRM has been given a high priority, especially among scientific circles, throughout the world for the past few decades (4). Numerous advancements in biosafety and biosecurity practices and procedures have emerged from this level of prioritization. Furthermore, through systematic awareness and capacity building, this has led to progress in the use of equipment and administrative controls, particularly in developed regions of the world (5). Despite the increased number of laboratory research and diagnostic settings in low and middle-income countries (LMICs), progress has been gradual (4-6).

Despite limited and inadequate funding allocated to BRM, Pakistan has made significant progress as a result of national and international organizations' efforts to raise awareness and build capacity. In Pakistan, however, public health, scientific research, veterinary medicine, and diagnostic laboratories face administrative and financial challenges. Pakistan currently has a number of challenges, including a strain on the health-care system due to its large population, a scarcity of health-care professionals, particularly in rural areas, a lack of oversight mechanisms, and limited resources allocated to improving or maintaining safe healthcare practices (7). Leadership and administration in many clinical and research settings in Pakistan are struggling to prioritize BRM due to an already overburdened healthcare system.

$\mathrm{KP}$ is Pakistan's third most populous province with a population of 30.52 million (8). KP hosts 11 private and 30 public universities and research institutes, 277 hospitals, and a number of diagnostic and biomedical facilities (9). In comparison to other provinces, a study conducted in KP in 2012 found that improper use of personal protective equipment (PPE), lack of proper sharps disposal mechanism, lack of standard operating procedure for laboratories, and accident reporting systems were the highest (9). Since 2012, a number of national and international organizations, as well as the Pakistani government, have been striving to build BRM capability and raise awareness in compliance with the GHSA and International Health Regulations (IHR) (811). These efforts have sensitized many stakeholders, including diagnostic laboratories, research institutions, and academics in taking responsibility and prioritizing BRM at their laboratory settings in Pakistan.

Since 2012, no survey for evaluating BRM systems in KP laboratories has been conducted. Furthermore, the 2012 study only examined only diagnostic or hospital settings (9). As a result, the purpose of this survey was to assess BRM systems in diagnostic and research laboratories in KP province in order to better identify the gaps and opportunities for future research and capacity-building efforts (9).

\section{MATERIALS AND METHODS}

For assessing and appraising laboratory BRM systems, a variety of tools and guidelines are available $(12,13)$. The questionnaire was developed in accordance with CWA 15793 (Biorisk management guidelines) and the WHO Laboratory Assessment Tool (2012) for evaluating BRM systems in KP laboratories for this study $(14,15)$. Both approaches have been utilized in a variety of settings. They cover a wide range of biosafety and biosecurity indicators, as well as practices and procedures, behaviors, safety and health services, waste disposal, and the use of personal protective equipment (PPE). The cross-sectional survey was conducted using an online questionnaire (12-15). The survey was conducted from September through November of 2016. Laboratory technicians, technologists, supervisors, quality control managers, postgraduate students, research officers, and faculty from universities, diagnostic, and research laboratories were the target respondents. Since we aimed to include institutes rather than individuals, convenience-based sampling was used to identify and recruit respondents for the survey. There were two components to the survey questionnaire. The first section of the questionnaire inquired about the type of laboratory and the respondents' titles and affiliations. The second section included questions about compliance and resource availability in the domains of PPE, safety and security procedures, behaviors, training, waste disposal protocol implementation, and health service information. Table 1 includes all the categories, variables, and questions included in the survey. All aspects assessed in these laboratories were given codes from Variable 1 (V1) to Variable 54 (V54).

\section{Ethics Statement}

According to approval from the Departmental Bioethics Committee, Department of Microbiology, Hazara University, Mansehra, Pakistan with letter number F.No.HU/MB/BEC/2016/10-05, informed consent was acquired from study participants, and respondents were informed that their participation in the survey was voluntary. No personal information was linked to the data acquired during analysis, and all responses were kept anonymous and confidential.

\section{Statistical Analysis}

SPSS 20.0 was used to analyze the data, and Microsoft Excel was used to generate the graphs. Depending on whether the laboratory was diagnostic or research-based, we segregated our results. PPE, biosafety behaviors, waste management, biosafety measures, biosecurity measures, training, and safety and health services were divided into seven groups for further stratification (Table 1).

\section{RESULTS}

\section{Participant Details}

A total of 30 laboratories from KP responded to the online survey, including 11 diagnostic and 19 research laboratories. 
TABLE 1 | The list of variables $(\mathrm{V})$ used for the cross-sectional survey to assess biorisk management system in research and diagnostic laboratories in Khyber Pakhtunkhwa, Pakistan.

\begin{tabular}{|c|c|c|c|c|c|}
\hline Indicator & $\mathbf{v}$ & Indicator & $\mathbf{v}$ & Indicator & Variable \\
\hline Lab coat & $\mathrm{v} 1$ & Use of liquid disinfection & v21 & Eyewash station & $\mathrm{v} 41$ \\
\hline Gloves & v2 & $\begin{array}{l}\text { Implementation status of liquid } \\
\text { disinfection }\end{array}$ & v22 & Emergency Shower & $\mathrm{v} 42$ \\
\hline Goggles & v3 & $\begin{array}{l}\text { Methods to ensure the efficacy of } \\
\text { disinfection }\end{array}$ & v23 & $\begin{array}{l}\text { Does your staff/students have access to } \\
\text { workers health services? }\end{array}$ & $\mathrm{v} 43$ \\
\hline $\begin{array}{l}\text { Where are coats and lab linens } \\
\text { washed? }\end{array}$ & v4 & $\begin{array}{l}\text { Are procedures for safe and secure } \\
\text { transport of culture, specimens, } \\
\text { samples, and other contaminated } \\
\text { materials effectively? }\end{array}$ & v24 & $\begin{array}{l}\text { Does your staff/students follow a regular yearly } \\
\text { visit to workers health services? }\end{array}$ & v44 \\
\hline $\begin{array}{l}\text { Is protective clothing of approved } \\
\text { design and fabric provided for all } \\
\text { staff/students for everyday work? }\end{array}$ & v5 & $\begin{array}{l}\text { Are the biosafety procedures available } \\
\text { at the bench level? }\end{array}$ & v25 & $\begin{array}{l}\text { Are individuals considered unfit for work on } \\
\text { health grounds identified and prevented from } \\
\text { accessing areas where there are risks of } \\
\text { exposure? }\end{array}$ & v45 \\
\hline PPE for Chemical and radiation & v6 & $\begin{array}{l}\text { Do you use biosafety cabinets to } \\
\text { manipulate samples producing } \\
\text { potentially dangerous aerosols? }\end{array}$ & v26 & $\begin{array}{l}\text { Are conditions that could impact personnel } \\
\text { associated with the facility addressed? These } \\
\text { may include medical conditions affecting work, } \\
\text { the ability to use appropriate PPE safely, or } \\
\text { factors affecting general well-being }\end{array}$ & v46 \\
\hline Face Shield & v7 & $\begin{array}{l}\text { Do you have a biohazard sign } \\
\text { indicated on the doors of the rooms } \\
\text { where microorganisms are handled? }\end{array}$ & v27 & Have the vaccination needs been identified? & v47 \\
\hline $\begin{array}{l}\text { Are staff prohibited from wearing the } \\
\text { protective clothing outside of the lab? }\end{array}$ & v8 & $\begin{array}{l}\text { Are warning and accident prevention } \\
\text { signs used to minimize work hazards? }\end{array}$ & v28 & Is there an immunization program for the lab? & $\mathrm{v} 48$ \\
\hline $\begin{array}{l}\text { Are staff prohibited from wearing } \\
\text { open-toed footwear? }\end{array}$ & v9 & $\begin{array}{l}\text { Are areas requiring vaccinations to } \\
\text { enter indicated? }\end{array}$ & v29 & $\begin{array}{l}\text { Are women of childbearing age warned of the } \\
\text { consequences of working with certain } \\
\text { microorganisms, carcinogens, mutagens, and } \\
\text { teratogens? }\end{array}$ & v49 \\
\hline $\begin{array}{l}\text { Are staff prohibited from eating, } \\
\text { drinking, smoke, or apply cosmetics } \\
\text { in the lab working areas? }\end{array}$ & v10 & $\begin{array}{l}\text { Are controls in place to ensure that } \\
\text { demand originates from legitimate } \\
\text { facilities and individuals? }\end{array}$ & v30 & $\begin{array}{l}\text { Are women of childbearing age told that if they } \\
\text { are, or suspect that they are, pregnant, they } \\
\text { should inform the appropriate medical/scientific } \\
\text { staff member so that alternative working } \\
\text { arrangements may be made for them if } \\
\text { necessary? }\end{array}$ & v50 \\
\hline $\begin{array}{l}\text { Is it prohibited to store food or drinks } \\
\text { in the lab working areas? }\end{array}$ & v11 & $\begin{array}{l}\text { Is access to lab areas restricted to } \\
\text { authorized personnel? }\end{array}$ & v31 & $\begin{array}{l}\text { Are first-aid boxes provided at strategic } \\
\text { locations? }\end{array}$ & v51 \\
\hline Is mouth pipetting forbidden? & v12 & $\begin{array}{l}\text { Is the whole building securely locked } \\
\text { when unoccupied? }\end{array}$ & v32 & Are qualified first-aiders available? & v52 \\
\hline $\begin{array}{l}\text { Do you have separate disposals for } \\
\text { infectious and non-infectious wastes? }\end{array}$ & v13 & $\begin{array}{l}\text { Are rooms containing hazardous } \\
\text { materials and expensive equipment } \\
\text { locked when unoccupied? }\end{array}$ & v33 & $\begin{array}{l}\text { Are such first-aiders trained to deal with } \\
\text { emergencies peculiar to the lab, e.g., contact } \\
\text { with corrosive chemicals, accidental ingestion } \\
\text { of poisons and infectious materials? }\end{array}$ & v53 \\
\hline $\begin{array}{l}\text { Do you have covered waste disposal } \\
\text { containers? }\end{array}$ & v14 & $\begin{array}{l}\text { Is access to such rooms, equipment } \\
\text { and materials appropriately controlled } \\
\text { and documented? }\end{array}$ & v34 & $\begin{array}{l}\text { Are notices prominently posted giving clear } \\
\text { information about first-aiders' location, } \\
\text { telephone numbers of emergency services, } \\
\text { etc.? }\end{array}$ & v54 \\
\hline $\begin{array}{l}\text { Do you have safe and adapted waste } \\
\text { containers? }\end{array}$ & v15 & $\begin{array}{l}\text { Have the staff/students been } \\
\text { presented with a biosafety manual? }\end{array}$ & v35 & & \\
\hline $\begin{array}{l}\text { Do you have special sharps } \\
\text { containers? }\end{array}$ & v16 & $\begin{array}{l}\text { Is training on "Biosafety while } \\
\text { sampling" required for your lab } \\
\text { staff/students before work? }\end{array}$ & v36 & & \\
\hline $\begin{array}{l}\text { Do you have dedicated waste for } \\
\text { used solvents? }\end{array}$ & v17 & $\begin{array}{l}\text { Is training on "Using disinfectants and } \\
\text { procedures in disinfection" required } \\
\text { for your lab staff/student before work? }\end{array}$ & v37 & & \\
\hline $\begin{array}{l}\text { Have all potential waste streams and } \\
\text { other sources of contamination been } \\
\text { identified and documented? }\end{array}$ & v18 & $\begin{array}{l}\text { Is training on "Proper waste } \\
\text { management" required for your lab } \\
\text { staff/students before work? }\end{array}$ & v38 & & \\
\hline $\begin{array}{l}\text { Is there an adequate organization for } \\
\text { the collection and disposal of general } \\
\text { household rubbish? }\end{array}$ & v19 & $\begin{array}{l}\text { Are refresher training on these topics } \\
\text { organized at least every } 3 \text { years? }\end{array}$ & v39 & & \\
\hline $\begin{array}{l}\text { Are discarded infectious materials } \\
\text { removed daily or more often and } \\
\text { disposed of safely? }\end{array}$ & v20 & $\begin{array}{l}\text { Were lab workers, e.g., domestic and } \\
\text { clerical staff, instructed on the lab's } \\
\text { potential hazards and the material it } \\
\text { handles? }\end{array}$ & $\mathrm{v} 40$ & & \\
\hline
\end{tabular}




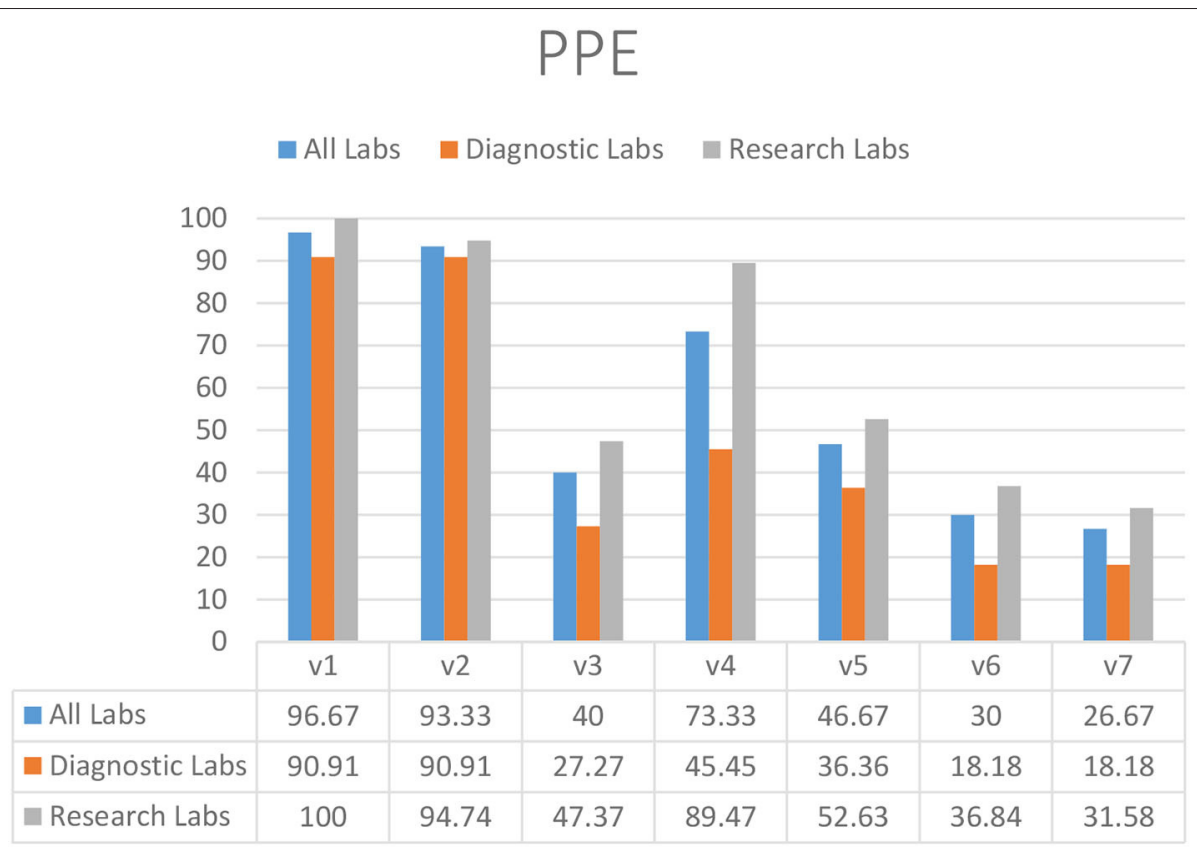

FIGURE 1 | Availability and appropriate usage of PPE in diagnostic and research laboratories in Khyber Pakhtunkhwa (KP), Pakistan.

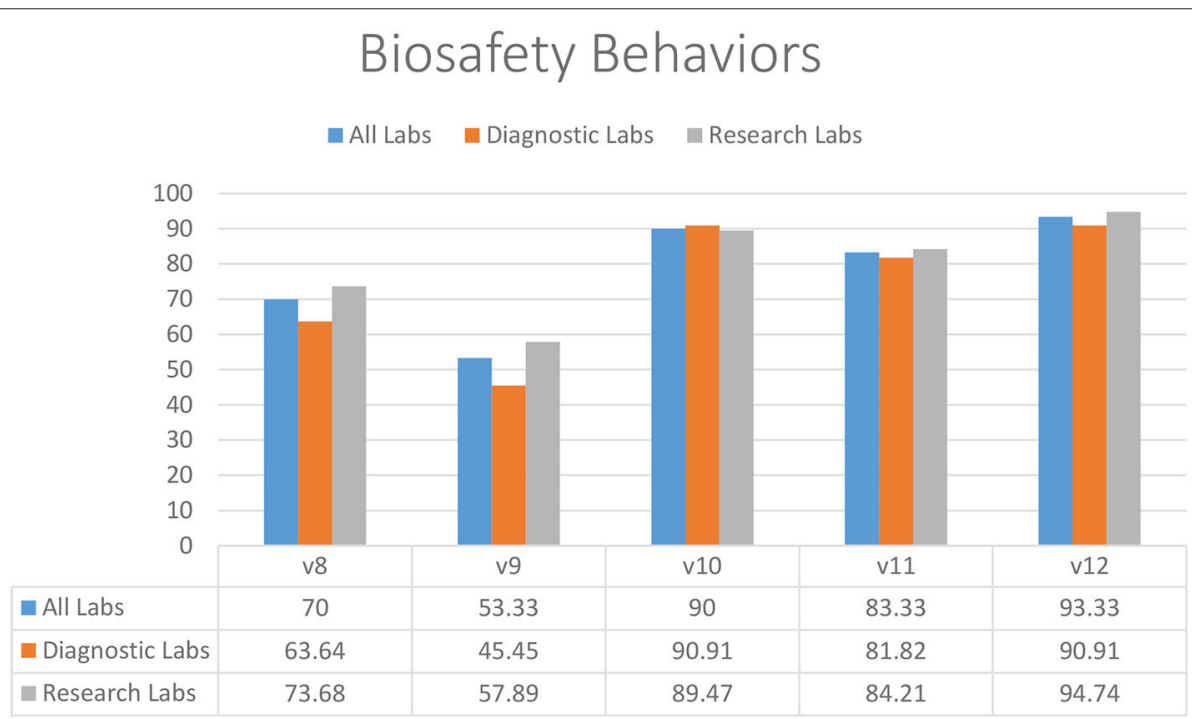

FIGURE 2 | Biosafety behaviors in diagnostic and research laboratories in Khyber Pakhtunkhwa (KP), Pakistan.

The respondents belonged to Swabi, Peshawar, Haripur, Mardan, Nowshehra, Mansehra, Kohat, Bannu, Swat, DI Khan, Dir regions of $\mathrm{KP}$.

\section{Personal Protective Equipment}

The majority of laboratories used gloves (93.33\%) (V2) and lab coats (96.67\%) (V1), although diagnostic laboratories demonstrated reduced compliance with the guideline that lab coats should not be washed at home (73.33\%) (V4) (Figure 1). Face shields (26.67\%) (V7), goggles (40.00\%) (V3), clothing of approved design and fabric (46.67\%) (V5), and PPE for chemical and radiation protection $(30.00 \%)$ (V6) were used and available in limited laboratories in KP (Figure 1).

\section{Biosafety Behaviors}

In the restrictions on food storage inside the laboratory (83.33\%) (V11), eating and drinking in the working area (90.00\%) (V10), and mouth pipetting (93.33\%) (V12), laboratories demonstrated substantial compliance (Figure 2). Almost half of diagnostic and research laboratories did not have a protocol in place to reduce or 


\section{Waste Disposal}

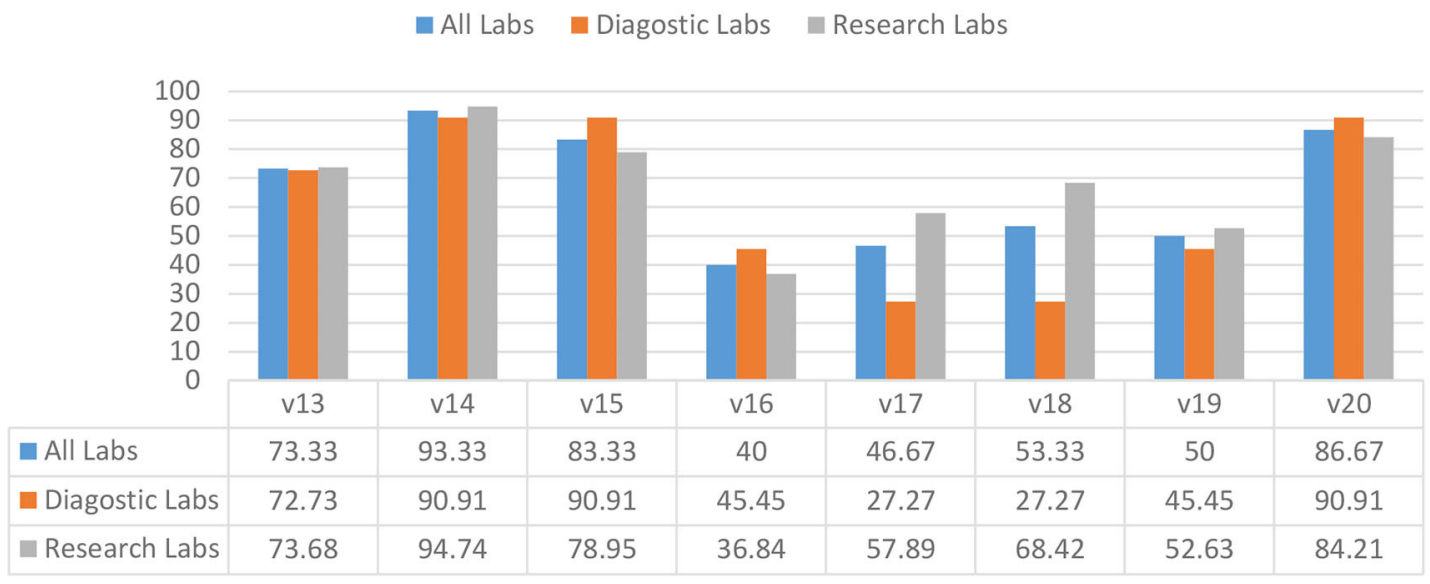

FIGURE 3 | Waste management practices in diagnostic and research laboratories in Khyber Pakhtunkhwa (KP), Pakistan.

limit the use of open footwear (53.33\%) (V9) in the lab (Figure 2). In addition, there was significantly less compliance with the restriction on wearing protective clothing outside of laboratories (70.00\%) (V8) (Figure 2).

\section{Waste Management}

Most of the diagnostic and research laboratories had separate disposal containers for infectious and non-infectious waste (73.33\%) (V13), excluding sharp containers (93.33\%) (V14) and biological waste containers available (83.33\%) (V15) (Figure 3). Almost half of the diagnostic (45.45\%) and research $(36.84 \%)$ labs did not have a dedicated sharps container available (V16). Discarded infectious materials were removed daily or more often in most laboratories (86.67\%) (V20). Diagnostic laboratories were struggling with having dedicated waste for used solvents (27.27\%) (V17) and identifying all potential waste streams (27.27\%) (V18). Most of the diagnostic and research laboratories also did not have an adequate organization for collecting and disposing of household rubbish (50.00\%) (V19).

\section{Biosafety Measures}

According to the survey results, the majority of diagnostic and research laboratories in $\mathrm{KP}$ were compliant in the use of liquid disinfectants (90.00\%) (V21), implementation of liquid disinfection $(90.00 \%)$ (V22), written biosafety procedures available at the bench (86.67\%) (V25), use of biosafety cabinets for aerosol-generating procedures (80.00\%) (V26), and display of accident prevention signs (73.33\%) (V28) (Figure 4). Several laboratories lacked indications of areas requiring vaccination (26.67\%) (V29), implementation of safe and secure sample transport (66.67\%) (V24), and display of biohazard signs on the doors of rooms where microorganisms are handled $(60.00 \%)$ (V27) (Figure 4).

\section{Biosecurity Measures}

Overall, the results showed that biosecurity measures were being followed in laboratories throughout the KP province (Figure 5). In most laboratories, access and security of laboratory settings (V31-34) were deemed adequate. "Controls in place to ensure demand originates from legitimate facilities or individuals" $(60.00 \%)$ (V30) was the most undermined biosecurity practice. The overall percentage of biosecurity controls and measures compliance $(80.67 \%)$ in $\mathrm{KP}$ province shows a positive picture in both research and diagnostic settings (Figure 5).

\section{Training}

Most laboratories required biosafety training for students and staff prior to sampling (83.33\%) (V36), the use of disinfectants (86.67\%) (V37), and proper waste management (86.67\%) (V38) (Figure 6). Fewer laboratories had mandatory 3-year refresher training (53.33\%) (V39) and training for auxiliary staff (56.67\%) (V40) (Figure 6). A biosafety manual was not available to $60.00 \%$ of the laboratory staff and students (V35) (Figure 6).

\section{Safety and Health Services}

Survey results indicated that laboratories had an ineffective immunization program (30.00\%) (V48) in their facilities (Figure 7). Diagnostic laboratories had better compliance for identifying the needs for vaccination (81.82\%) (V47) and an annual visit to health services by staff members (63.64\%) (V44), as compared to the research laboratories (Figure 7). This compliance might be due to the affiliation of most diagnostic laboratories with hospital settings. In almost half of the laboratories, access to first aid boxes (63.33\%) (V51) and qualified first aiders were missing (V52-53). A similar pattern was seen for safety and health variables relevant to pregnancy and childbearing age while working in a laboratory (V49-50) (Figure 7). Most of the laboratories did not have an eyewash station (16.67\%) (V41). 


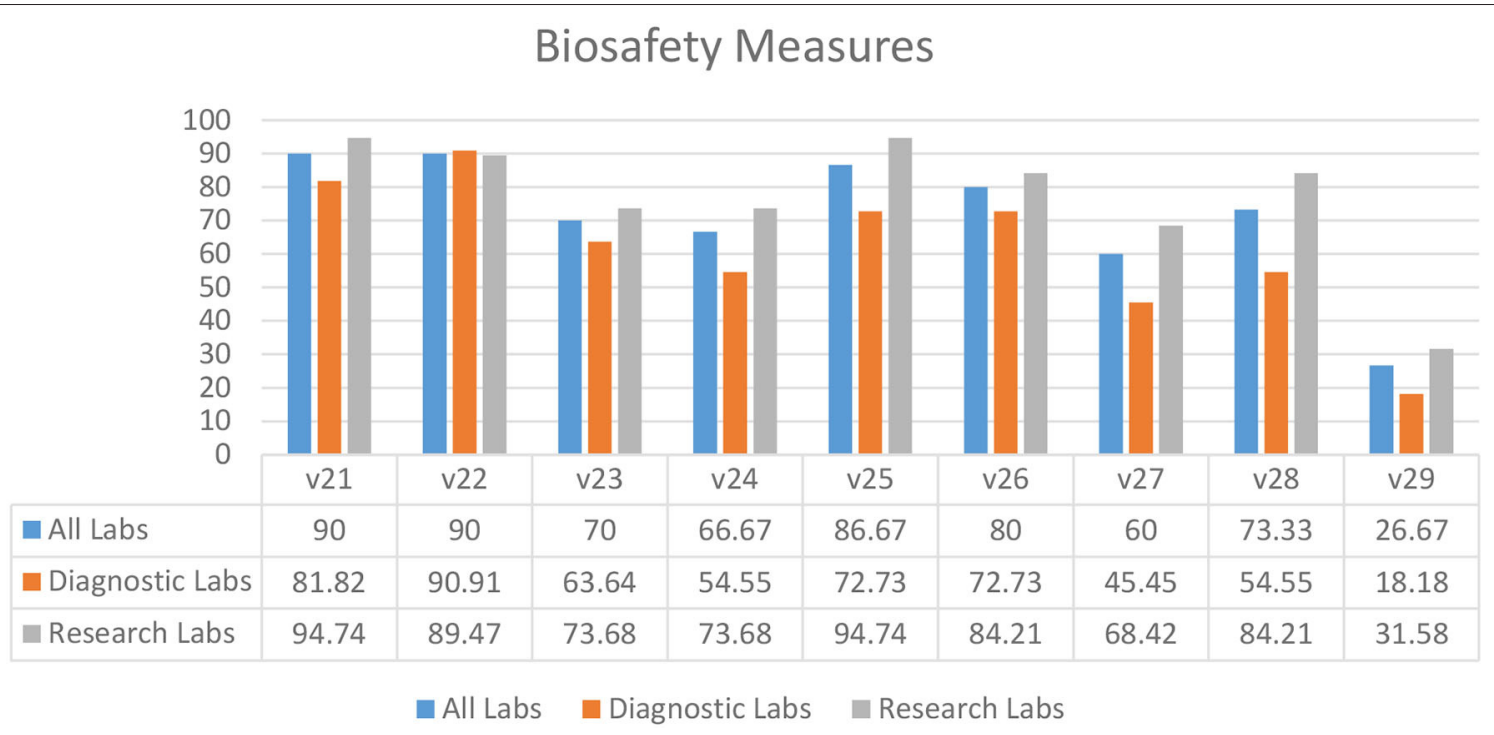

FIGURE 4 | Biosafety measures in diagnostic and research laboratories in Khyber Pakhtunkhwa (KP), Pakistan.

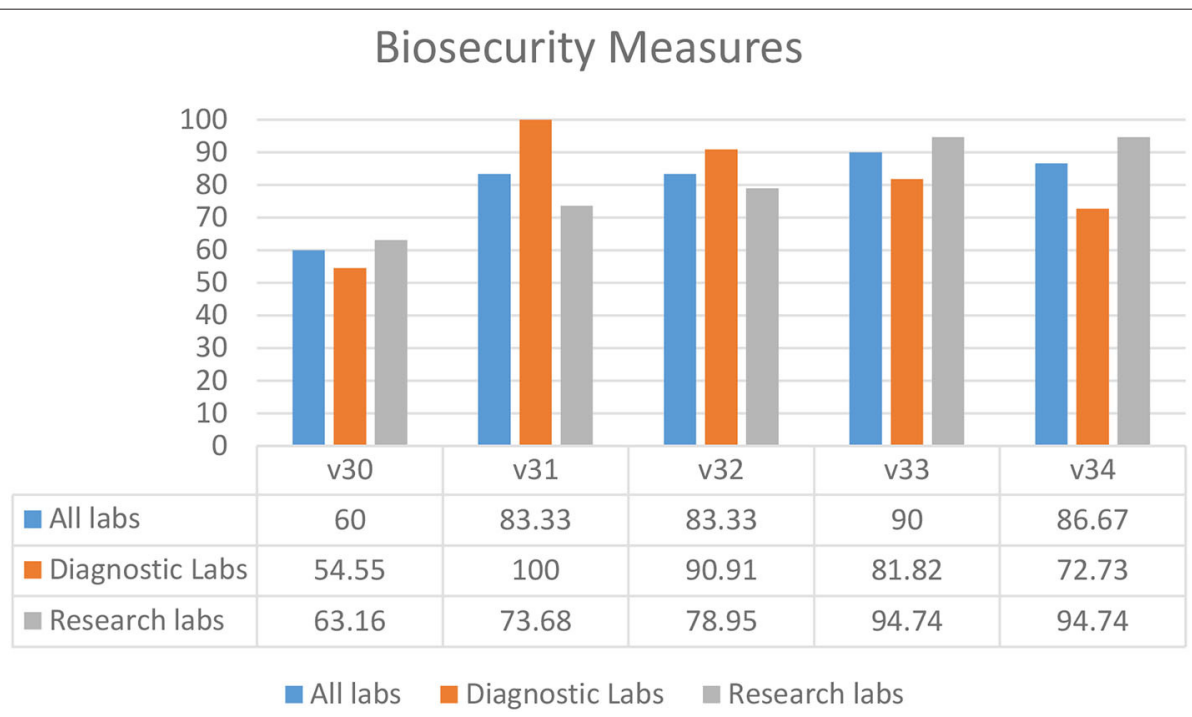

FIGURE 5 | Biosecurity measures in diagnostic and research laboratories in Khyber Pakhtunkhwa (KP), Pakistan.

\section{DISCUSSION}

\section{Diagnostic Laboratories Comparison: 2012 and 2016}

In 2012, a cross-sectional survey in Pakistan evaluated BRM systems in diagnostic settings (9). Nasim et al. created a diagnostic laboratory questionnaire that included questions about routine laboratory practices, mouth pipetting, PPE, disinfection methods, and specimen handling and collection. We compared our 2016 data to the results of the survey conducted in 2012 (9) to assess the current state of BRM systems in diagnostic laboratories and any progress made over time
(Figure 8). We found eight standard variables in both data sets. When the data was compared, all eight variables show significant improvements (9). Despite the low level of sharps container compliance in KP (45.4\%) in 2016, there has been a significant improvement from 11.2 percent of diagnostic laboratories in 2012. Since 2012, the use of biosafety cabinets, the absence of food and drink in the work area, the availability of gloves and lab coats, and biosafety and security training have all improved significantly. Many national and international organizations have been working with Pakistani laboratories to improve BRM systems in recent years, and this significant improvement can be attributed to them. 


\section{Trainings}

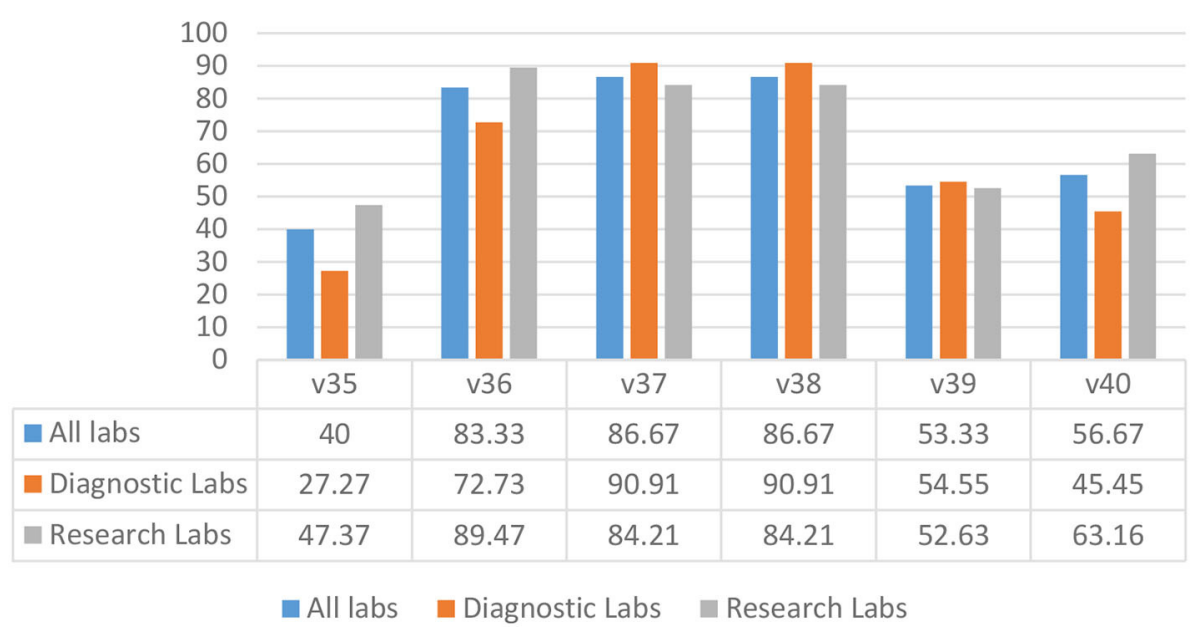

FIGURE 6 | Training practices in diagnostic and research laboratories in Khyber Pakhtunkhwa (KP), Pakistan.

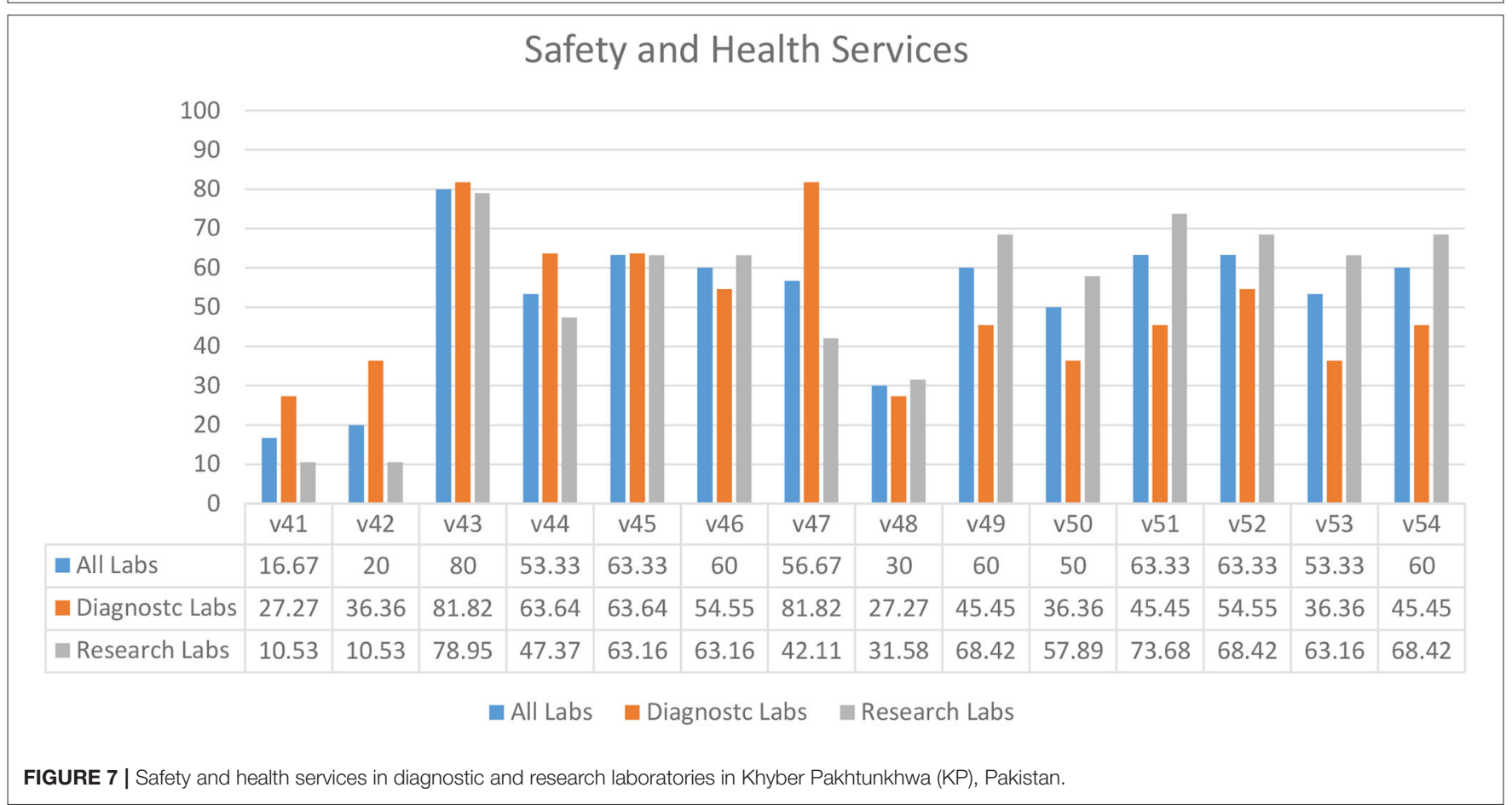

In 2018, another study looked at the impact of training on BRM practices at five universities in one of KP's districts (16). According to Rashid and colleagues, 82 percent of the students had received BRM training and were found to have the knowledge and skills to properly use PPE, manage waste, and respond to emergencies (15). Rashid et al., on the other hand, found a significantly lower compliance rate in some universities, indicating the need for additional interventions to put the knowledge and skills learned during these trainings into practice. Further research into the reasons for resource constraints and low leadership engagement and priority toward BRM should be investigated to identify specific factors impeding implementation $(15,16)$.

A 2017 study in KP assessed compliance with hospital waste management rules in 44 public and private hospitals, uncovering serious shortcomings in the hospital waste management systems (1). However, when compared to the previous study, our findings revealed significant improvements in the waste management system in KP laboratories (9). This disparity could be explained by the sample investigated, as we were looking at waste management in laboratories rather than hospitals. Some significant deficiencies in the laboratories' health and 


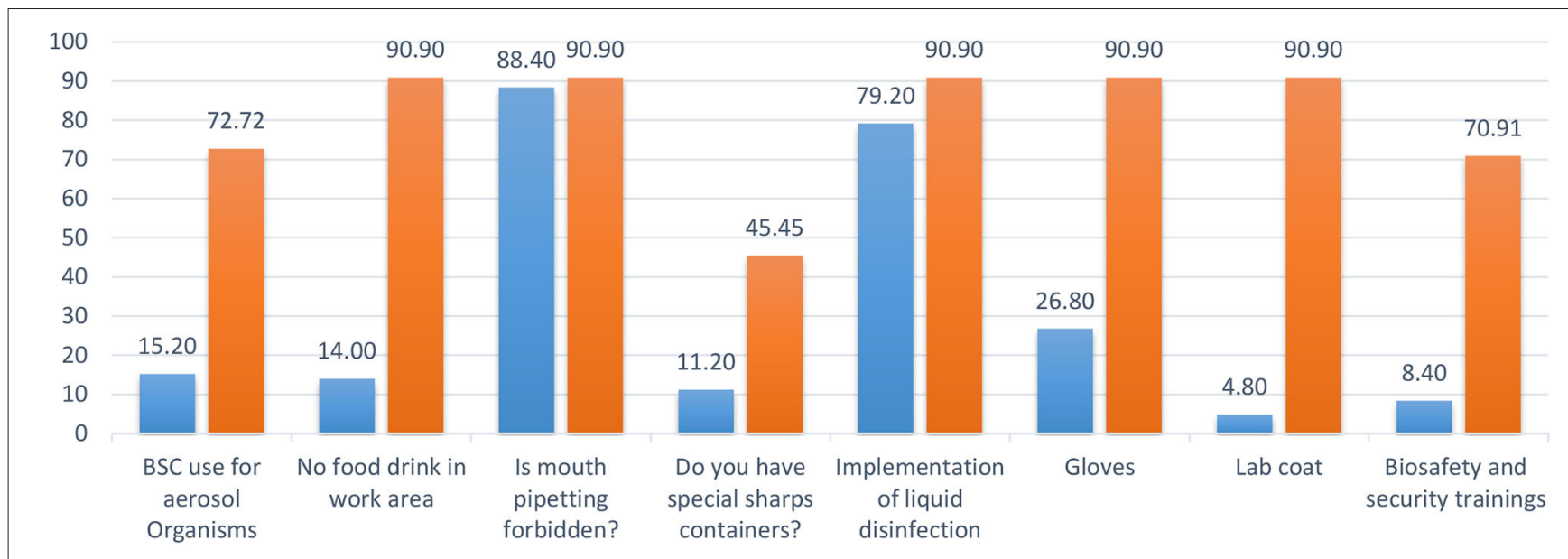

safety services were found during our investigation. In these laboratories, a robust occupational health and medical/incident surveillance program should be prioritized for long-term improvement and evaluation (9).

\section{Follow-Up Activities and Progress Related to the Improvement of Biorisk Management System Across Institutions}

Since 2014, the Pakistan Biological Safety Association (PBSA) has collaborated with the Fogarty International Center on the BioPrism flagship program to develop biosafety practices in Pakistan. The program employed a three-tiered trainingof-trainers approach. Sixty professionals are being taught the fundamentals of biosafety from all over the country. Pre- and post-tests are used to assess their understanding of the concepts as well as the training's effectiveness. At the end of training, each participant is asked to demonstrate the skills they gained. Top achievers were selected to participate in a 5-day "master trainer" course to improve their presentation and communication skills. Verbal exams were conducted after the master trainer course to assess the trainers' comprehension of the subject, delivery, and communication skills. Each trainer is assigned a topic to present, and their skills were assessed depending on how successfully they do so. High scorers were then selected for a third, more intensive "wet workshop." At the completion of the session, the high achievers were given the title of master trainer. All participants, including master trainers, should first train at least seven individuals and report to PBSA. These trainings were successful in establishing a network of dedicated and well-trained biosafety professionals. PBSA has launched a new series of workshops in Pakistan called Responsible Conduct in the Life Sciences. Participants should train at least seven people and report to the PBSA, including master trainers. In the same way that the BioPrism program prepares participants to become trainers, these seminars do as well (17). Multiple workshops on high-reliability organization, influence without authority, and waste management were held at the national and regional levels by PBSA and FIC/NIH in conjunction with biorisk management experts. In addition, the program's trainers have been offered support in conducting training in their individual institutions to promote biorisk management principles (17).

\section{CONCLUSION}

The laboratories in KP are evidently working hard to improve their BRM systems and practices, as indicated by this study. These efforts must be reinforced, with a focus on continuous improvement, which is critical for successful BRM systems. Continual improvement necessitates thorough inspections and audits of BRM systems to identify nonconformities. This study provides an overview of the current BRM systems' strengths and areas for improvement. Despite the fact that leadership engagement has become so vital in this process, more research is needed to determine how to gain public sector leadership to invest and prioritize BRM for continued improvement.

\section{DATA AVAILABILITY STATEMENT}

The original contributions presented in the study are included in the article/supplementary material, further inquiries can be directed to the corresponding author/s.

\section{ETHICS STATEMENT}

The studies involving human participants were reviewed and approved by Departmental Bioethics Committee, Department of Microbiology, Hazara University, Mansehra, Pakistan 
with letter number F.No.HU/MB/BEC/2016/10-05. The patients/participants provided their written informed consent to participate in this study.

\section{AUTHOR CONTRIBUTIONS}

JM: conceptualization, methodology, writing, and review and editing. SS: conceptualization, methodology, project administration, and review and editing. SQ, AI, and TK: critical review. GA: statistical analysis and interpretation. $\mathrm{MZ}$ and $\mathrm{RD}$ : writing the first draft of results and discussion. FA: writing of

\section{REFERENCES}

1. Coelho AC, García Díez J. Biological risks and laboratory-acquired infections: a reality that cannot be ignored in health biotechnology. Front Bioeng Biotechnol. (2015) 3:56. doi: 10.3389/fbioe.2015.00056

2. Bathula SR, Rakhimol A. Global trends in biorisk management. BioRisk. (2017) 12:1. doi: 10.3897/biorisk.12.12156

3. Farradika Y, Lisdawati V, Roehaeni R, Suwandono A. Dominant factors associated with biosafety facility and equipment in laboratories: an Indonesian 2011 study. Health Sci J Indonesia. (2013) 4:1-6.

4. Khan E, Ahmed N, Temsamani KR, El-Gendy A, Cohen M, Hasan A, et al. Biosafety initiatives in BMENA region: identification of gaps and advances. Front Public Health. (2016) 4:44. doi: 10.3389/fpubh.2016.00044

5. Sture J, Whitby S, Perkins D. Biosafety, biosecurity and internationally mandated regulatory regimes: compliance mechanisms for education and global health security. Med Confl Surviv. (2013) 29:289-321. doi: 10.1080/13623699.2013.841355

6. Vos T, Abajobir AA, Abate KH, Abbafati C, Abbas KM, Abd-Allah F, et al. Global, regional, and national incidence, prevalence, and years lived with disability for 328 diseases and injuries for 195 countries, 1990-2016: a systematic analysis for the Global Burden of Disease Study 2016. Lancet. (2017) 390:1211-59. doi: 10.1016/S0140-6736(17)32154-2

7. Ittefaq M, Iqbal A. Digitization of the health sector in Pakistan: challenges and opportunities to online health communication: a case study of MARHAM social and mobile media. Dig Health. (2018) 4:2055207618789281. doi: $10.1177 / 2055207618789281$

8. Pakistan Bureau of Statistics. Province Wise Provisional Results of Census-2017. Pakistan Bureau of Statistics Islamabad (2017).

9. Nasim S, Shahid A, Mustufa MA, Arain GM, Ali G, Talreja KL, et al. Biosafety perspective of clinical laboratory workers: a profile of Pakistan. J Infect Dev Countries. (2012) 6:611-9. doi: 10.3855/jidc.2236

10. Burkle FM Jr. Global health security demands a strong international health regulations treaty and leadership from a highly resourced World Health Organization. Disaster Med Public Health Prep. (2015) 9:568-80. doi: $10.1017 / \mathrm{dmp} .2015 .26$

11. World Health Organization. International Health Regulations 2005. Geneva: WHO (2008).

12. Mouillé B, Dauphin G, Wiersma L, Blacksell SD, Claes F, Kalpravidh $\mathrm{W}$, et al. Tool for assessment of animal health laboratory safety the original draft, statistical analysis and interpretation of the data, and supervision. All authors contributed to the article and approved the submitted version.

\section{ACKNOWLEDGMENTS}

We would like to appreciate and recognize Pakistan Biological Safety Association for their cooperation in conducting the survey, as well as Health Security Partners USA for their financial support for this study. We'd also want to thank everyone who took part in the study for taking the time to complete the survey.

and biosecurity: the safety module of the Food and Agriculture Organization's Laboratory Mapping Tool. Trop Med Infect Dis. (2018) 3:33. doi: $10.3390 /$ tropicalmed 3010033

13. Sijnesael PC, van den Berg LM, Bleijs DA, Odinot P, de Hoog C, Jansen MW, et al. Novel Dutch self-assessment biosecurity toolkit to identify biorisk gaps and to enhance biorisk awareness. Front Public Health. (2014) 2:197. doi: 10.3389/fpubh.2014.00197

14. World Health Organization. Laboratory Quality Management System: Handbook. Lyon: World Health Organization (2011).

15. de Normalisation CE. NORMUNG EKF. Laboratory Biorisk ManagementGuidelines for the Implementation of CWA 15793:2008. Brussels: CENCENELEC Management Centre (2012).

16. Rashid F, Fatima S, Jalal S. The impact of biosafety trainings on knowledge and attitudes of life sciences students towards biosafety in Hazara, Khyber Pakhtunkhwa, Pakistan. Infect Dis Health. (2018) 23:S1. doi: 10.1016/j.idh.2018.09.002

17. Khan T, Tanveer F, Muhammad J. Improving biosecurity in Pakistan: current efforts, challenges, and recommendations on a multidimensional management strategy. Health Secur. (2021) 19:254-61. doi: $10.1089 /$ hs. 2020.0050

Conflict of Interest: The authors declare that the research was conducted in the absence of any commercial or financial relationships that could be construed as a potential conflict of interest.

Publisher's Note: All claims expressed in this article are solely those of the authors and do not necessarily represent those of their affiliated organizations, or those of the publisher, the editors and the reviewers. Any product that may be evaluated in this article, or claim that may be made by its manufacturer, is not guaranteed or endorsed by the publisher.

Copyright () 2021 Muhammad, Sarwar, Khan, Qasmi, Ikram, Ahmad, Zahid, Durrani and Ahmed. This is an open-access article distributed under the terms of the Creative Commons Attribution License (CC BY). The use, distribution or reproduction in other forums is permitted, provided the original author(s) and the copyright owner(s) are credited and that the original publication in this journal is cited, in accordance with accepted academic practice. No use, distribution or reproduction is permitted which does not comply with these terms. 